\title{
Texture Selection Mechanisms during Recrystallization and Grain Growth of a Magnesium-Erbium-Zinc Alloy
}

\author{
Fatim-Zahra Mouhib *, Fengyang Sheng, Ramandeep Mandia, Risheng Pei $\mathbb{D}^{\mathrm{D}}$, Sandra Korte-Kerzel (D) and \\ Talal Al-Samman (D)
}

Citation: Mouhib, F.-Z.; Sheng, F.; Mandia, R.; Pei, R.; Korte-Kerzel, S.; Al-Samman, T. Texture Selection Mechanisms during Recrystallization and Grain Growth of a

Magnesium-Erbium-Zinc Alloy. Metals 2021, 11, 171. https:// doi.org/10.3390/met11010171

Received: 29 December 2020

Accepted: 15 January 2021

Published: 19 January 2021

Publisher's Note: MDPI stays neutral with regard to jurisdictional claims in published maps and institutional affiliations.

Copyright: (c) 2021 by the authors. Licensee MDPI, Basel, Switzerland. This article is an open access article distributed under the terms and conditions of the Creative Commons Attribution (CC BY) license (https:/ / creativecommons.org/licenses/by/ $4.0 /)$.
Institute for Physical Metallurgy and Materials Physics, RWTH Aachen, 52056 Aachen, Germany; fengyang.sheng@rwth-aachen.de (F.S.); rmandia@asu.edu (R.M.); pei@imm.rwth-aachen.de (R.P.); korte-kerzel@imm.rwth-aachen.de (S.K.-K.); alsamman@imm.rwth-aachen.de (T.A.-S.)

* Correspondence: mouhib@imm.rwth-aachen.de

Abstract: Binary and ternary $\mathrm{Mg}-1 \% \mathrm{Er} / \mathrm{Mg}-1 \% \mathrm{Er}-1 \% \mathrm{Zn}$ alloys were rolled and subsequently subjected to various heat treatments to study texture selection during recrystallization and following grain growth. The results revealed favorable texture alterations in both alloys and the formation of a unique $\pm 40^{\circ}$ transvers direction (TD) recrystallization texture in the ternary alloy. While the binary alloy underwent a continuous alteration of its texture and grain size throughout recrystallization and grain growth, the ternary alloy showed a rapid rolling (RD) to transvers direction (TD) texture transition occurring during early stages of recrystallization. Targeted electron back scatter diffraction (EBSD) analysis of the recrystallized fraction unraveled a selective growth behavior of recrystallization nuclei with TD tilted orientations that is likely attributed to solute drag effect on the mobility of specific grain boundaries. Mg- $1 \% \mathrm{Er}-1 \% \mathrm{Zn}$ additionally exhibited a stunning microstructural stability during grain growth annealing. This was attributed to a fine dispersion of dense nanosized particles in the matrix that impeded grain growth by Zener drag. The mechanical properties of both alloys were determined by uniaxial tensile tests combined with EBSD assisted slip trace analysis at $5 \%$ tensile strain to investigate non-basal slip behavior. Owing to synergic alloying effects on solid solution strengthening and slip activation, as well as precipitation hardening, the ternary $\mathrm{Mg}-1 \% \mathrm{Er}-1 \% \mathrm{Zn}$ alloy demonstrated a remarkable enhancement in the yield strength, strain hardening capability, and failure ductility, compared with the Mg-1\%Er alloy.

Keywords: magnesium-rare earth alloy; recrystallization; selective grain growth; texture

\section{Introduction}

As of late, there is an increasing trend for using magnesium alloys in the automotive and aerospace industries owing to their excellent specific strength properties and lightweighting potential. However, a broad technical application of wrought magnesium alloy products still struggles with the difficulty to form at temperatures below $150{ }^{\circ} \mathrm{C}$ caused by the formation of a sharp basal texture and limited activation of deformation modes outside of the basal plane [1,2]. Great research efforts have been explored to not only alter the sharp sheet texture but also to control its strength and evolution [2-4]. Magnesium rare earth (RE) alloys have proven very useful in enhancing the cold formability and the work hardening capability of conventional magnesium alloys. This has been attributed to the development of a unique sheet annealing texture characterized by an off-basal pole spread away from the normal direction of the sheet plane [4-7]. Numerous recrystallization and growth mechanisms were explored in an attempt to unravel the underlying mechanisms for the favorable texture development in magnesium rare earth alloys. These included particle stimulated nucleation, deformation twin nucleation, and shear band nucleation mechanisms, which are known to promote random orientations or off-basal orientations of recrystallization nuclei [8]. However, since these mechanisms can also occur in magnesium 
alloys containing no RE elements [9-11], the research on the origin of the specific texture selection in Mg-RE alloys is still ongoing.

Recent studies in that context looked into a connection between RE solutes and oriented nucleation/growth during recrystallization, given that specific RE-textures have been observed in dilute alloys in which the RE elements were mostly in solid solution. It was also shown that the addition of zinc to Mg-RE alloys has proven to further weaken the texture and augment its off-basal nature [12]. Hence, more studies are needed to investigate the interaction of multiple solute species, particularly ones with largely different atomic radii $[12,13]$. Additionally, it is essential to examine how different RE and non-RE soluteboundary interactions impact the growth selection during texture evolution in $\mathrm{Mg}-\mathrm{RE}$ and Mg-RE-Zn alloys.

This study aims at understanding the formation of unique sheet textures and the ensuing selection mechanisms in Er-containing magnesium alloys with and without the presence of $\mathrm{Zn}$. Reports on this alloy system with respect to deformation and recrystallization textures are scarce in the literature. It is therefore important to illustrate the great texture modification potential the present alloys have to offer. In particular, the formation of a double-peak split texture in the transverse direction, similar to what is common for hexagonal metals with $\mathrm{c} / \mathrm{a}<1.633$, is a unique feature that is hardly seen in $\mathrm{Mg}$ alloys subjected to rolling and annealing treatments. The discussion addresses the texture development in both binary and ternary versions of the alloy during recrystallization and grain growth under the influence of solutes and second phase precipitates.

\section{Materials and Methods}

Binary and ternary Mg-1\%Er-(1\%Zn) (wt \%) alloys were melted in an induction furnace under an $\mathrm{Ar} / \mathrm{CO}_{2}$ gas atmosphere and subsequently casted and homogenized at $420{ }^{\circ} \mathrm{C}$ for $960 \mathrm{~min}$. The resulting microstructure is shown in Figure 1. Table 1 shows the chemical composition measured by ICP/OES (IME RWTH University, Aachen, Germany). Sheets of the dimension $60 \times 40 \times 4 \mathrm{~mm}^{3}$ were hot rolled at $400{ }^{\circ} \mathrm{C}$ with multiple rolling passes (eleven) and a final thickness reduction of $80 \%$.

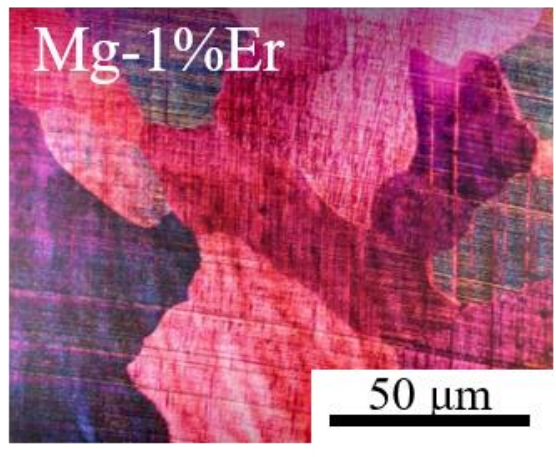

(a)

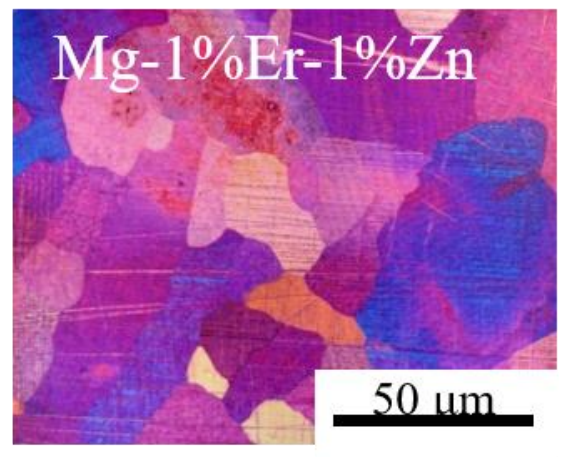

(b)

Figure 1. Micrographs of Mg-1\%Er (a) and Mg-1\%Er-1\%Zn (b) after casting.

Table 1. Chemical composition in atomic and weight percentage of $\mathrm{Mg}-1 \% \mathrm{Er}$ and $\mathrm{Mg}-1 \% \mathrm{Er}-1 \% \mathrm{Zn}$.

\begin{tabular}{ccccccc}
\hline Alloys & \multicolumn{2}{c}{ Mg (wt \%/at \%) } & \multicolumn{2}{c}{ Er (wt \%/at \%) } & \multicolumn{2}{c}{ Zn (wt \%/at \%) } \\
\hline Mg-Er & 99.04 & 99.86 & 0.96 & 0.14 & \multicolumn{2}{c}{$/$} \\
Mg-Er-Zn & 98.01 & 99.46 & 0.93 & 0.14 & 1.06 & 0.40 \\
\hline
\end{tabular}

Annealing treatments at $350{ }^{\circ} \mathrm{C}$ and $400{ }^{\circ} \mathrm{C}$ were conducted in a Heraeus RL200E air furnace (Heraeus Group, Hanau, Germany) for annealing times ranging from 5 to $1440 \mathrm{~min}$ and in a sand bath furnace for annealing times smaller than $5 \mathrm{~min}$. 
All samples were mechanically ground to the specimen mid-plane and polished with a diamond suspension up to $0.25 \mu \mathrm{m}$. For optical light microscopy (Leica microsystems, Wetzlar, Germany), the samples were electro-polished for $40 \mathrm{~min}$ in a 5:3 ethanol $\mathrm{H}_{3} \mathrm{PO}_{3}$ solution at $2 \mathrm{~V}$ and etched in an acetic picral solution. Grain size measurements from light microscopy images were performed by means of the linear intercept method. Texture measurements were conducted using a Bruker D8 advance diffractometer (Bruker, Billerica, MA, USA) operating at $30 \mathrm{~V}$ and $25 \mathrm{~mA}$. Six incomplete pole figures $[\{10 \overline{1} 0\}$, $\{0002\},\{10 \overline{1} 1\},\{10 \overline{1} 2\},\{11 \overline{1} 0\},\{10 \overline{1} 3\}]$ were measured, from which full pole figures and orientation distribution functions (ODFs) were calculated with the texture analysis toolbox MTEX (MTEX 5.3, Chemnitz, Germany) [14]. For selected samples intended for electron backscatter diffraction (EBSD) analysis under the electron beam an alternative electro-polishing procedure was employed using Lectro-Pol 5 in a Struers AC-2 solution at a voltage of $25 \mathrm{~V}$ and $-20{ }^{\circ} \mathrm{C}$ for $120 \mathrm{~s}$. Microstructure analysis via EBSD was performed using a LEO-1530 scanning electron microscope (Carl Zeiss Microscopy GmbH, Jena, Germany) operating at $20 \mathrm{kV}$, equipped with a HKL-Nordlys II EBSD detector. The detection step size varied according to the grain size in a range from 0.5 to $1.5 \mu \mathrm{m}$. EBSD and X-Ray diffraction (XRD) raw data were analyzed using the MTEX toolbox [14].

For the characterization of precipitates panorama back scatter electron (BSE)imaging (50 images per specimen) was conducted under a magnification of $10,000 \times$ with a focused ion beam Helios 600i (Thermo Fisher Scientific, Waltham, MA, USA) equipped with a field emission electron gun operating at $5 \mathrm{kV}$.

Recrystallization (RX) kinetics for both alloys were obtained by Vickers micro-hardness measurements (HMV, Shimadzu, Nakagyo-ku, Kyōto, Japan) (load of 1 N) of specimens subjected to interrupted annealing at $350{ }^{\circ} \mathrm{C}$ for durations up to $1000 \mathrm{~s}$. For each annealing condition, 15 indentations were used to determine the average hardness $H V_{t}$ at time step $t$. The recrystallized fraction was calculated by the common Equation (1), where $H V_{\text {initial }}$ and $H V_{\text {final }}$ denote the initial and final hardness values, respectively [15].

$$
X=\frac{H V_{\text {initial }}-H V_{t}}{H V_{\text {initial }}-H V_{\text {final }}}
$$

The mechanical properties were determined by uniaxial tensile tests at room temperature conducted along the rolling direction on fully recrystallized samples of both alloys. The tensile samples were carefully chosen to have a similar grain size in order to exclude grain size effects on the yield strength response of the material. Dog-bone-shaped samples with gauge dimensions of $5 \times 1.5 \times 0.8 \mathrm{~mm}^{3}$ were cut out of the rolling sheets and subsequently annealed at $400{ }^{\circ} \mathrm{C}$ for 15 and $60 \mathrm{~min}$ for the binary and ternary alloys, respectively. Tensile tests were conducted using a ZWICK tension-compression testing machine. Specimens were strained under a constant strain rate of $2 \times 10^{-4}$ to failure. Each tensile test was performed three times to ensure reproducibility and the average flow curve was considered for the analysis. In order to determine the operating slip systems during uniaxial tension, interrupted tensile tests were performed up to $5 \%$ strain on samples annealed at $400{ }^{\circ} \mathrm{C}$ for $60 \mathrm{~min}$ of both alloys. Subsequently, the slip systems were determined by comparison of slip lines from secondary electron (SE) images obtained at $20 \mathrm{kV}$ and the grain orientations determined by EBSD of at least 120 grains each.

\section{Results}

\subsection{Microstructure Evolution}

Figure 2 shows the optical microstructures of rolled and annealed samples of the binary and ternary $\mathrm{Mg}-1 \% \mathrm{Er}-(1 \% \mathrm{Zn})$ alloys. The annealing temperature was $400{ }^{\circ} \mathrm{C}$ and the annealing times were 15 and $360 \mathrm{~min}$, respectively. The corresponding XRD textures, presented in terms of (0002) pole figures, as well as the evolution of the average grain size as a function of the annealing time are given in Figure 3. As it can be seen, both alloys exhibited a common deformation microstructure characterized by deformed grains and numerous deformation twins. The rolling texture of the binary alloy showed a typical basal 
component with a pole spread towards the rolling direction (RD) and moderate intensity. On the other hand, the ternary alloy exhibited a weaker and much softer rolling texture characterized by two off-basal components at $\pm 20^{\circ} \mathrm{RD}$ that bare a significant pole spread in the transverse direction TD.

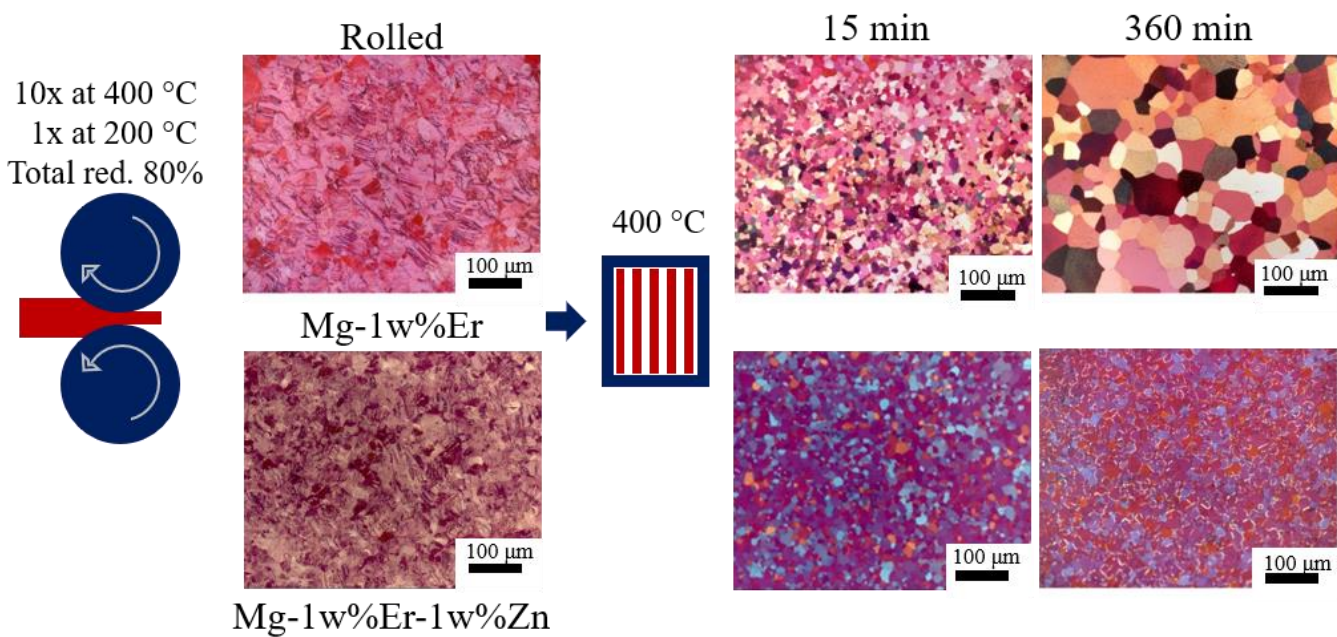

Figure 2. Micrographs of Mg-1\%Er and $\mathrm{Mg}-1 \% \mathrm{Er}-1 \% \mathrm{Zn}$ in the as-rolled state and upon annealing at $400{ }^{\circ} \mathrm{C}$ for 15 and $360 \mathrm{~min}$. The images are taken from the rolling plane (mid-thickness).

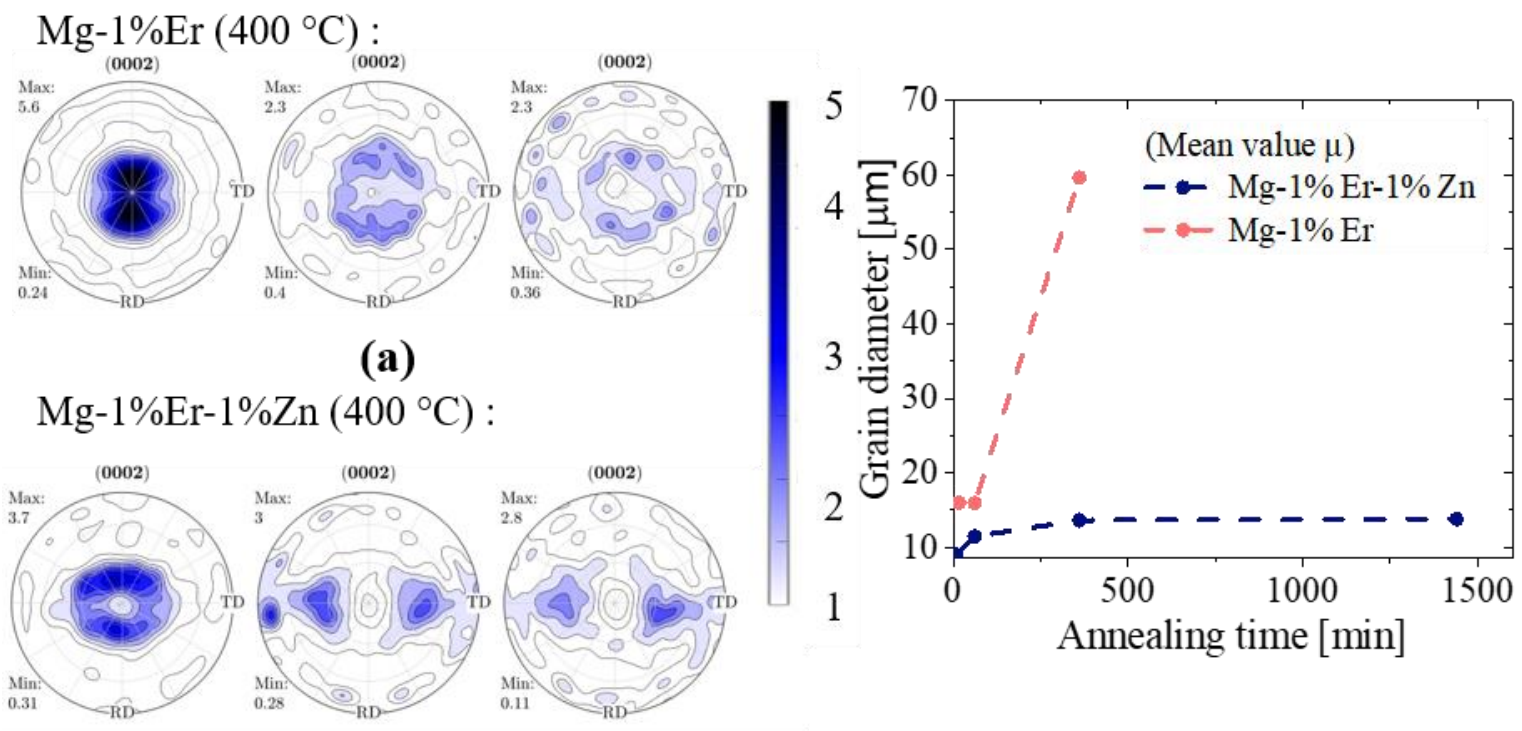

(b)

(c)

Figure 3. Texture evolution of binary and ternary (a,b) Mg-1\%Er-(1\%Zn) in the as rolled state and after annealing at $400{ }^{\circ} \mathrm{C}$ for 15 and $360 \mathrm{~min}$, as well as the corresponding evolution of the mean grain diameter over time (c).

During a subsequent heat treatment at $400{ }^{\circ} \mathrm{C}$, the ternary alloy seemed to develop a fine-grained annealing microstructure with a stable grain size $(14 \mu \mathrm{m})$ that was not liable to additional grain growth at increased annealing durations (Figure 2). The corresponding annealing texture witnessed a unique transition demonstrated by new off-basal components appearing at $\pm 40^{\circ} \mathrm{TD}$. This type of annealing texture after rolling is only common for hcp metals like titanium [16], that have a lower c/a ratio than the ideal ratio of 1.633 for close-packed structures, and can thus easily activate prismatic and pyramidal slip. As to the binary alloy, it exhibited an initially stable grain size $(16 \mu \mathrm{m})$ up to an annealing time of $60 \mathrm{~min}$ but underwent significant grain growth $(60 \mu \mathrm{m})$ after $360 \mathrm{~min}$ of annealing 
(Figure 3c). The texture of the binary Mg- $1 \% \mathrm{Er}$ alloy during early annealing conserved the dominant pole split in RD seen in the deformation texture but was also significantly weakened as a result of recrystallization (5.6 MRD $\rightarrow 2.3 \mathrm{MRD}$ ). With prolonged annealing up to $360 \mathrm{~min}$, the texture spread around the normal direction ND seemed to increase during grain growth and the basal component in the center of the pole figure has vanished.

Given the interesting nature of the texture transition seen upon annealing of the $\mathrm{Mg}$ $1 \% \mathrm{Zn}-1 \%$ Er alloy, additional annealing experiments were carried out at a lower temperature of $350{ }^{\circ} \mathrm{C}$. The annealing durations were kept short-i.e., up to $15 \mathrm{~min}-$ in order to capture the effect of early recrystallization stages on the texture transition. The results are shown in Figure 4, which demonstrates how the $\pm 20^{\circ}$ RD deformation texture transforms into a $\pm 40^{\circ} \mathrm{TD}$ annealing texture accompanied by full recrystallization of the specimen. Figure 5 shows the distribution of the basal poles (or c-axes) with respect to the rolling and transvers directions for the ternary (bottom) and binary alloy (top) along with their inverse pole figure (IPF) maps at $400{ }^{\circ} \mathrm{C} / 360 \mathrm{~min}$. Based on the annealing durations, the data clearly reveals that the texture established during recrystallization in the ternary alloy is preserved during subsequent grain growth, as the orientation distribution relative to the TD and RD remains virtually unchanged (Figure 5c). In case of the binary alloy, the total area fraction of grains with a large TD pole spread increases significantly with the annealing duration, whereas the area distribution of the RD spread remains almost constant (Figure $5 b$ ).
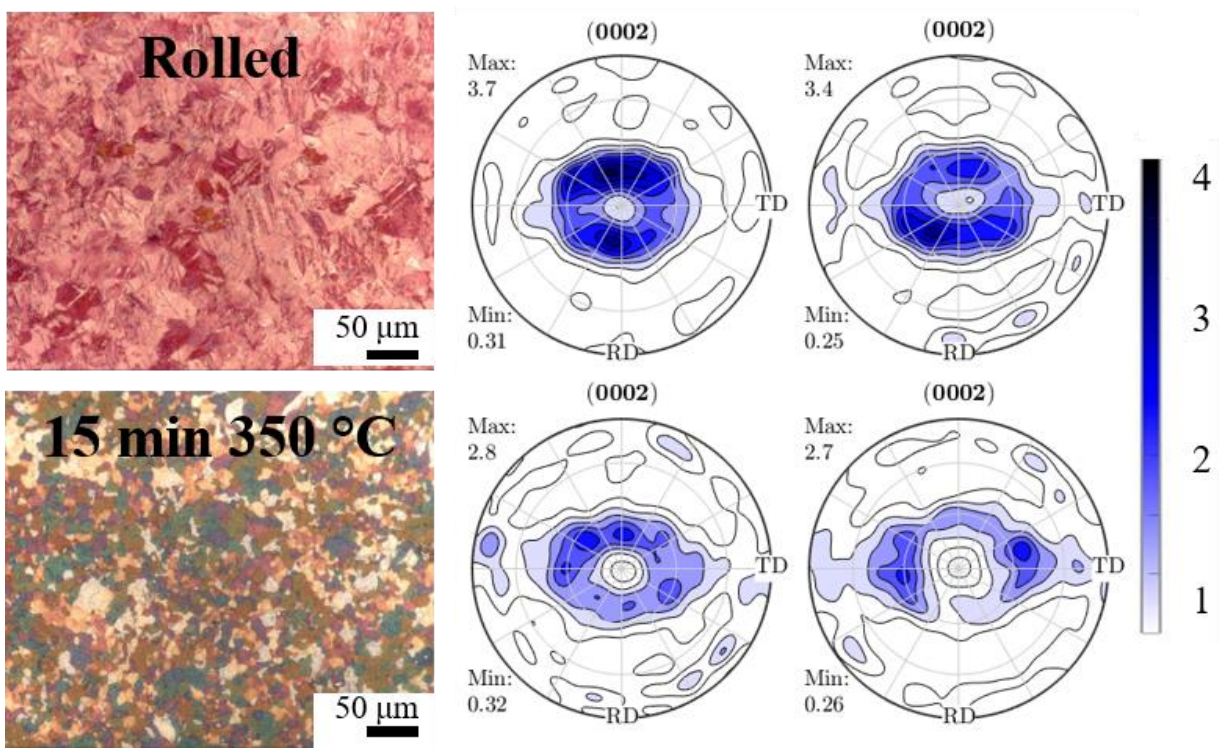

Figure 4. Texture evolution during recrystallization of Mg- $1 \%$ Er- $1 \% \mathrm{Zn}$ annealed at $350{ }^{\circ} \mathrm{C}$ for $0,5,7$, and $15 \mathrm{~min}$.

With respect to second phase precipitates in the microstructure, the ternary alloy was found to exhibit a fine distribution of nano-scale precipitates and also larger ones that were sometimes clustered together, as shown in Figure 6. Energy dispersive X-ray spectroscopy (EDS) point analysis and elemental mapping were employed to investigate the chemical composition of these large precipitates. The results revealed a particle composition with a magnesium to zinc to erbium ratio of approximately 5:5:1. A similar zinc to erbium ratio was previously reported for several hexagonal and icosahedral quasi-crystalline $(\mathrm{Mg}, \mathrm{Zn})_{x} \operatorname{Er}$ compounds $[17,18]$. 


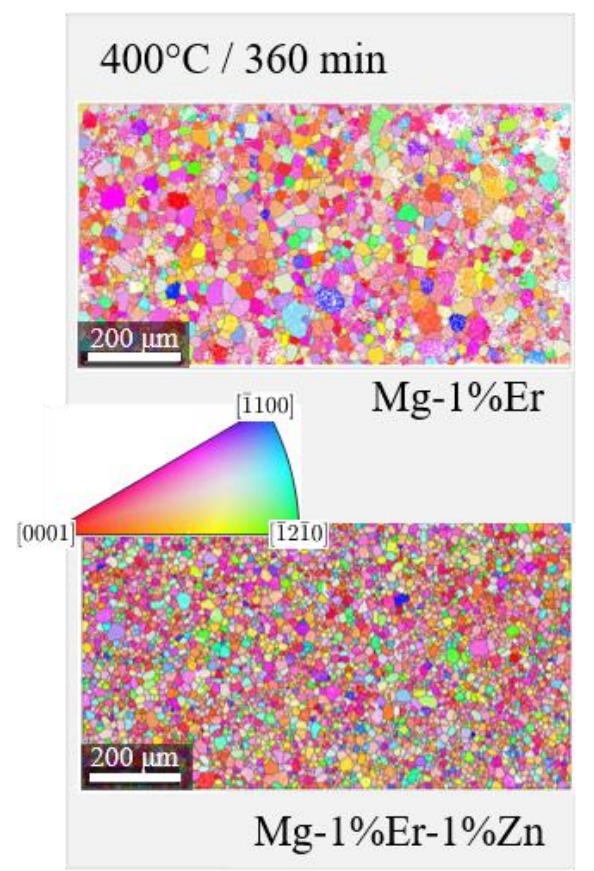

(a)
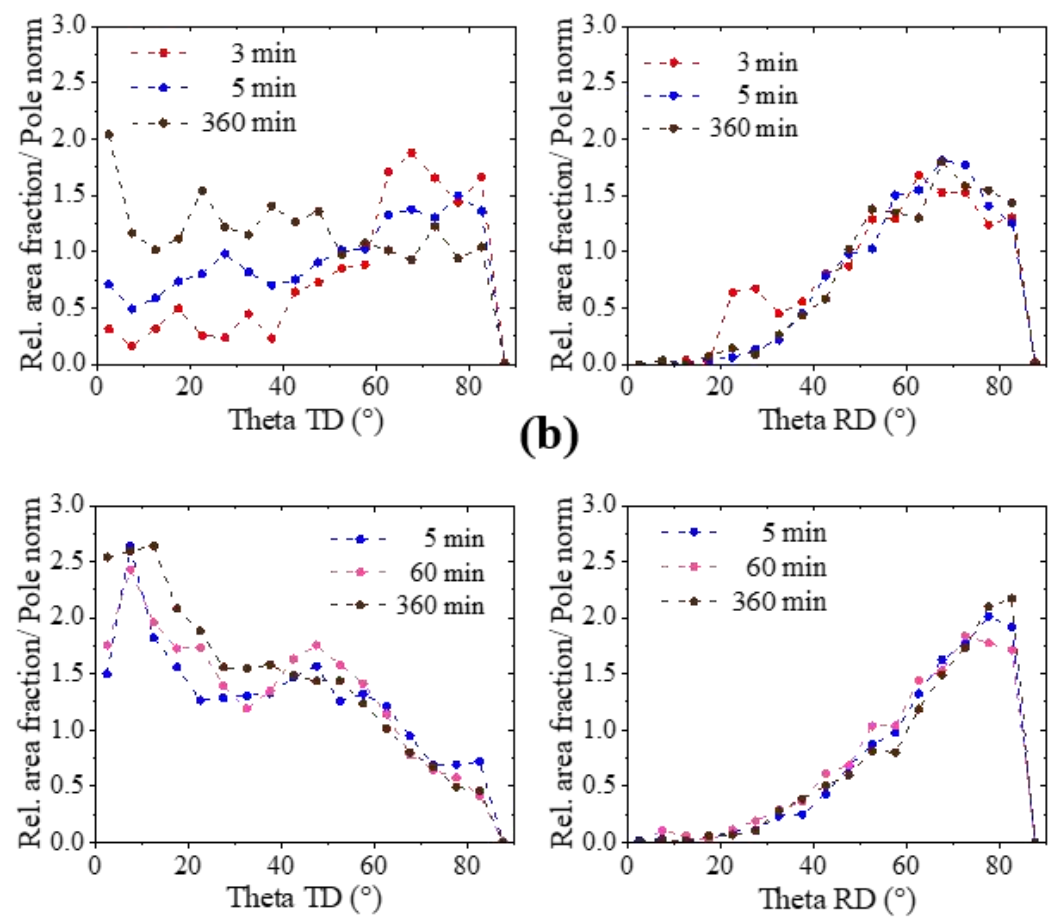

(c)

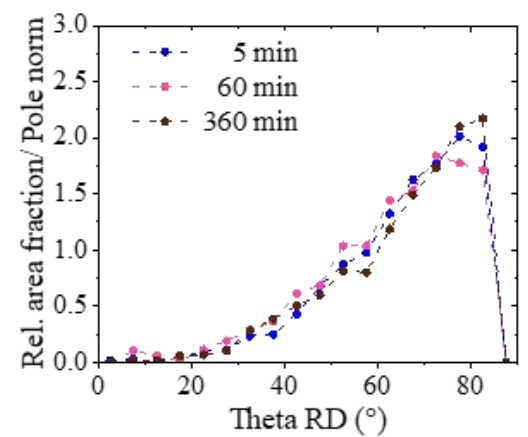

Figure 5. (a) EBSD ND-IPF maps of binary (top) and ternary Mg-1\%Er-(1\%Zn) (bottom) alloys annealed at $400{ }^{\circ} \mathrm{C}$ for $360 \mathrm{~min}$; $(\mathbf{b}, \mathbf{c})$ angle distribution profiles between the c-axis and the transverse and rolling directions for different annealing durations.

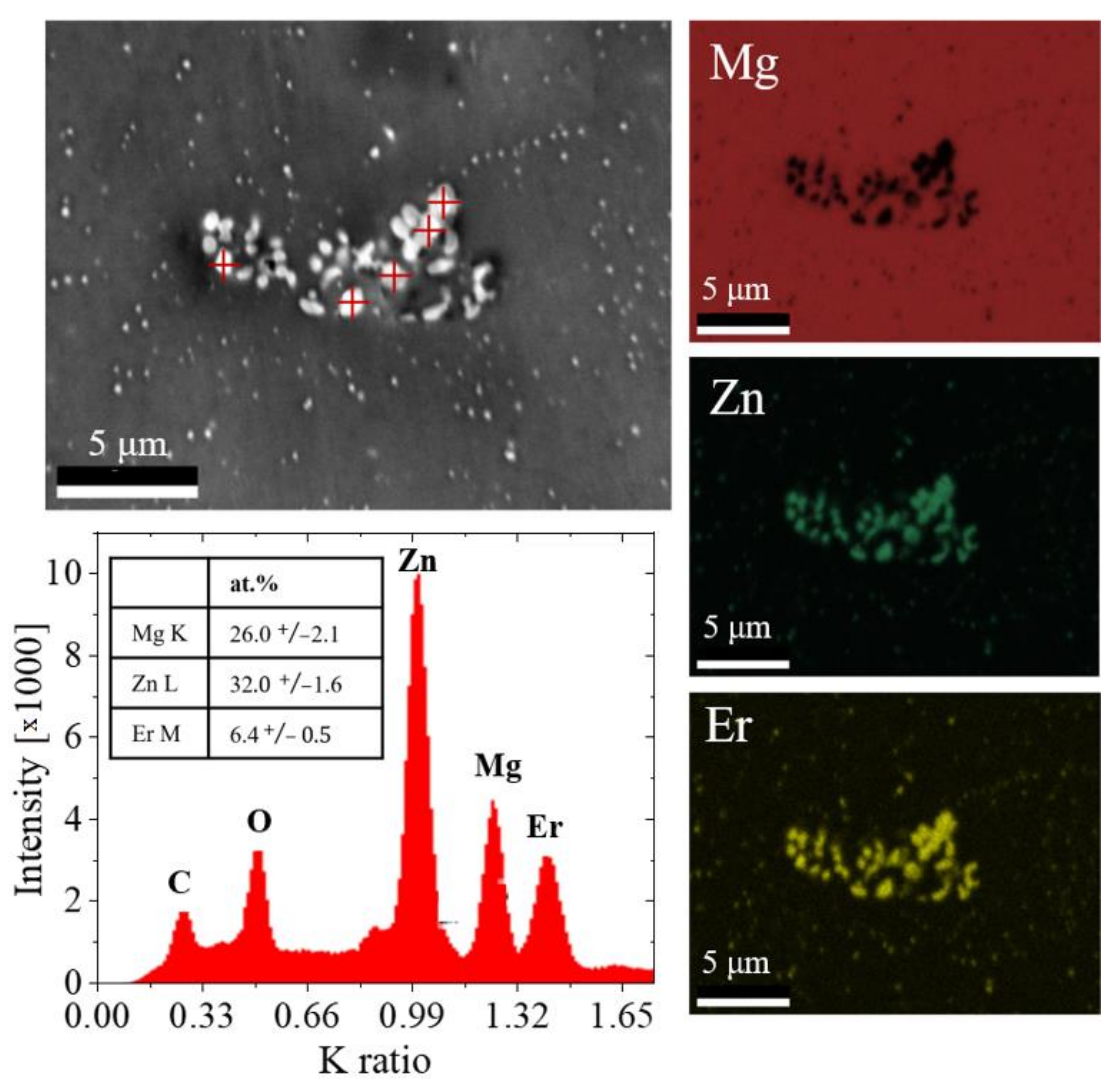

Figure 6. EDS analysis of the Er-containing precipitates observed in the Mg- $1 \%$ Er- $1 \% \mathrm{Zn}$ alloy. 


\subsection{Mechanical Properties}

Figure 7a shows the true stress-strain curves of the uniaxial tensile tests in $\mathrm{RD}, 45^{\circ}$ and TD for the investigated alloys annealed at $400{ }^{\circ} \mathrm{C}$ for 15 and $60 \mathrm{~min}$, respectively. The samples of both alloys exhibited a similar annealing grain size (hence the different times) but a drastically different texture (Figure $7 \mathrm{~b}$ ). As evident from the flow curves, the addition of zinc leads to higher ductility, as well as an increase of the ultimate tensile strength, which are indicative of an enhanced work hardening capability.

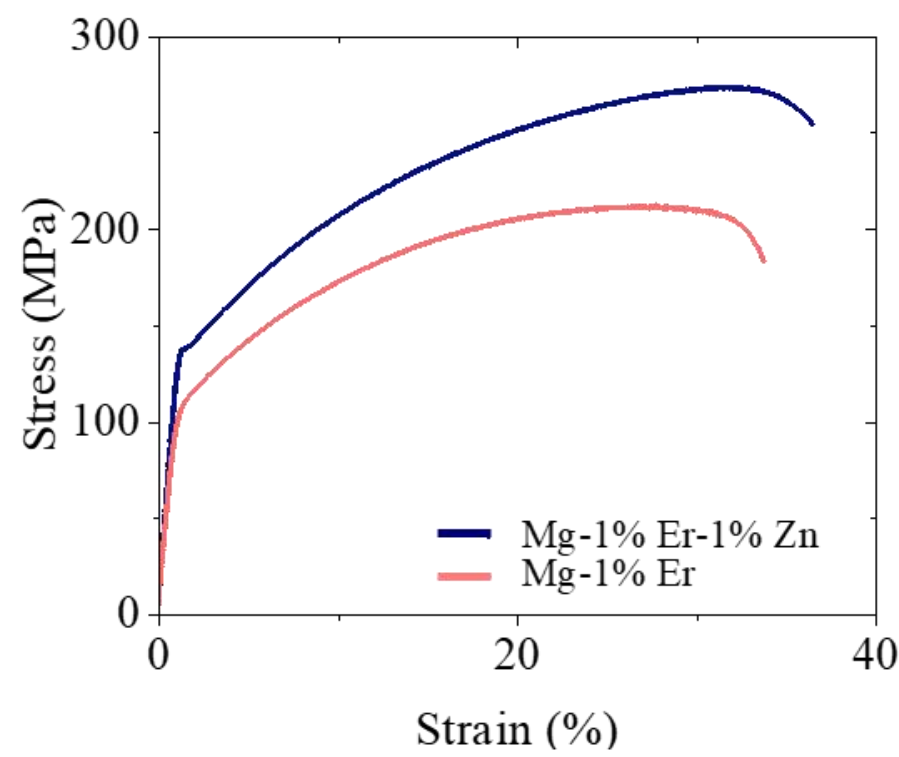

(a)

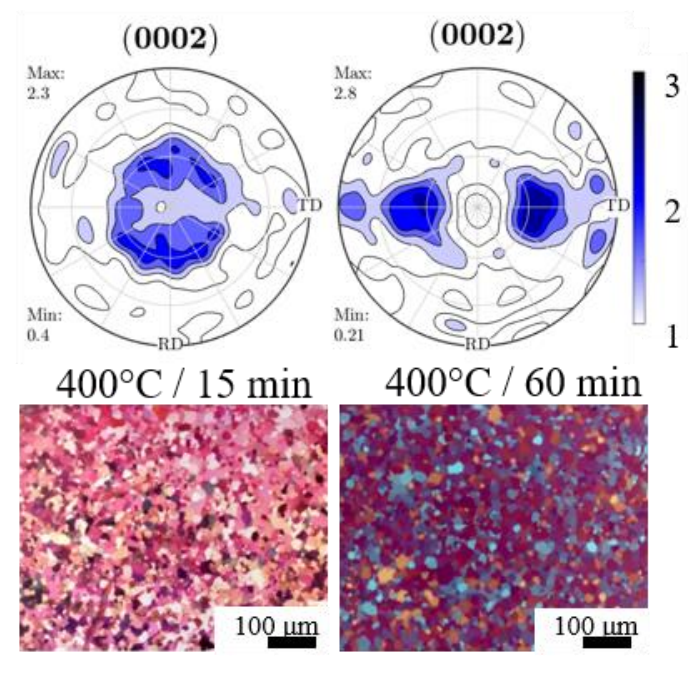

(b)

Figure 7. Uniaxial stress-strain response (a), optical micrographs and (0002) pole figures of Mg-1\%Er annealed for 15 min and $\mathrm{Mg}-1 \% \mathrm{Er}-1 \% \mathrm{Zn}$ annealed for $60 \mathrm{~min}$ at $400{ }^{\circ} \mathrm{C}(\mathrm{b})$. The grain size prior to the tensile test was in the range of 14 to $16 \mu \mathrm{m}$ for both samples.

\section{Discussion}

The present study revealed distinct differences in the microstructure evolution and mechanical properties between a dilute Mg-1\%Er alloy with and without the addition of Zn. During annealing, both alloys developed a significant basal pole spread away from the ND. For the ternary alloy, a titanium rolling texture with off-basal components at $\pm 40^{\circ}$ TD developed during recrystallization, and was retained during subsequent grain growth By contrast, the recrystallization texture of the binary alloy with off-basal peaks at $\pm 20^{\circ}$ $\mathrm{RD}$ was further modified with longer annealing resulting in a much larger grain size and increased texture scatter. The stable grain size in the $\mathrm{Mg}-1 \% \mathrm{Er}-1 \% \mathrm{Zn}$ alloy in contrary to the excessive growth in $\mathrm{Mg}-1 \% \mathrm{Er}$ can be explained by the presence of a fine particle dispersion and the resulting drag force (Zener drag). This is known to have a significant impeding effect on the grain boundary motion and can therefore lead to a stable grain size $[19,20]$. Figure 8 shows a BSE image of the observed precipitates in Mg-1\%Er-1\%Zn after $60 \mathrm{~min}$ of annealing at $400{ }^{\circ} \mathrm{C}$ and the corresponding particle size distribution. The precipitate characteristics including particle size, volume fraction, and number density are listed in Table 1. 


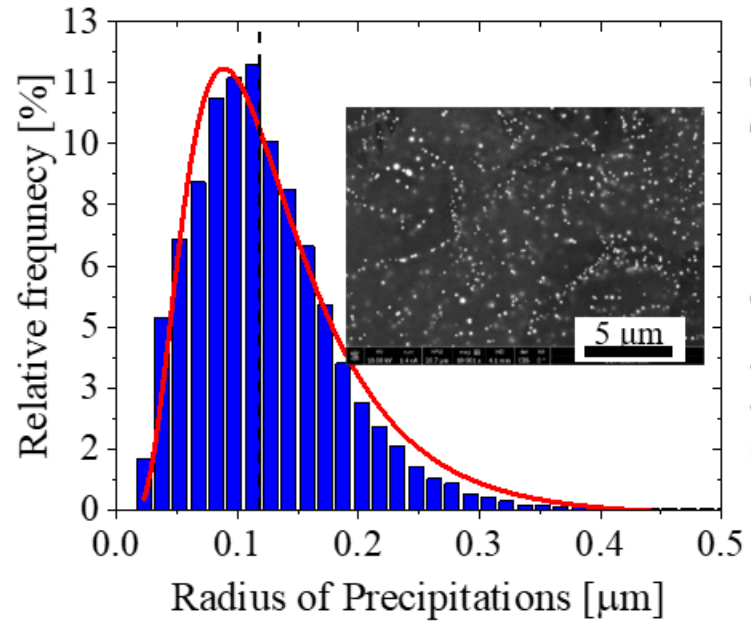

(a)

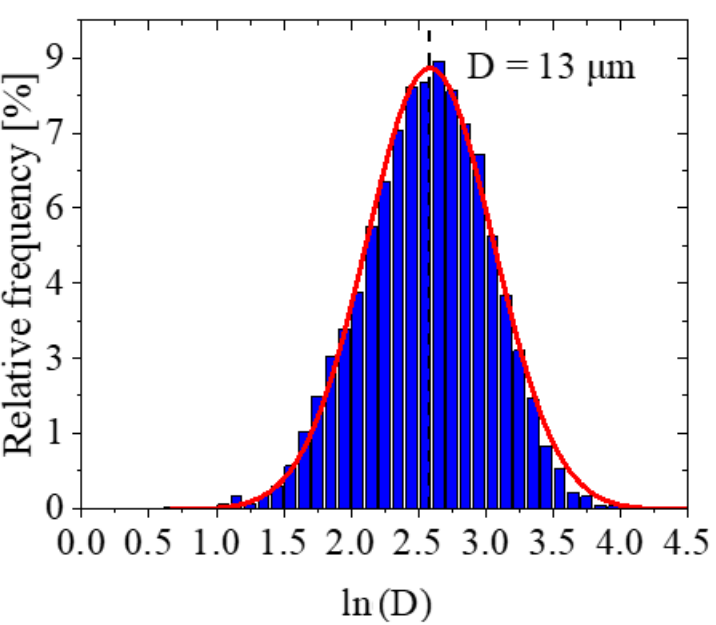

(b)

Figure 8. Particle size distribution after $60 \mathrm{~min}$ of annealing at $400^{\circ} \mathrm{C}$ visualized using a histogram with linear $x$-axis (a) and the corresponding grain size distribution obtained by optical microscopy $(\mathbf{b})$.

The critical grain size according to classical Zener theory is given by Equation (2), assuming that the radius of curvature equals the critical grain diameter [20].

$$
D_{c}=\frac{4 r}{3 f}
$$

The calculated critical grain size of $12 \mu \mathrm{m}$, obtained by using the values in Table 2, is similar to the measured grain size $(13.28 \mu \mathrm{m})$ under the same annealing conditions (cf. Figure $8 \mathrm{~b}$ ). This supports the assumption made earlier that the fine precipitates stabilize the recrystallization microstructure during annealing. Similarly, the absence of precipitates in the binary alloy $(\mathrm{Mg}-1 \% \mathrm{Er})$ could explain the excessive growth rate observed after an initial slow growth stage during the first $15 \mathrm{~min}$ of annealing (cf. Figure 3). The drag force during this short stage is believed to be caused by solutes inhibiting the motion of grain boundaries [21-23], which were obviously able to break free after 15 min annealing time. Theoretical studies revealed that accelerated grain growth in a system under the influence of solute pinning will occur when the average grain size becomes close to the critical grain size for which the solute drag force and the capillary driving force are equal. Such state allows the pinned boundaries with a slightly higher curvature than the average to break free from their solute atmosphere, while the other boundaries remain pinned [24]. This seems to be in accordance with the observed growth behavior of the Mg- $1 \%$ Er alloy and the resulting growth of non-basal texture components (cf. Figure 5b) after a critical grain size has been reached.

Table 2. Characteristics of the Er and Zn-containing precipitates in Mg-1\%Er-1\%Zn obtained by means of statistical analysis of BSE images

\begin{tabular}{ll}
\hline Volume Fraction f: & 0.0131 \\
\hline Average Particle Size r: & $0.122 \mu \mathrm{m}$ (from dist. 0.1178) \\
\hline Number density: & $0.22461 / \mu \mathrm{m}^{2}$ \\
\hline
\end{tabular}

In the ternary alloy, the process of recrystallization was responsible for the RD $\rightarrow$ TD transition of the basal pole spread seen in Figure 4, which can be contributed to either oriented nucleation or selective nucleus growth. Selective growth of texture components can be caused by anisotropic segregation behavior and/or an equalization of different grain boundary mobilities annihilating a prior growth advantage of certain orientations, e.g., 
of basal oriented grains as suggested by Barrett et al. [25]. Figure 9 presents EBSD maps (ND-IPF) of the microstructure of the ternary alloy at 5 and 10 min annealing at $350{ }^{\circ} \mathrm{C}$. The orientation of recrystallized grains was evaluated separately from the orientation of the overall microstructure in order to discern the effect of recrystallization on the development of the $\pm 40^{\circ} \mathrm{TD}$ texture. For this, the common criterion of grain orientation spread (GOS) was used, where recrystallized grains typically depicted GOS $<1^{\circ}$. The overall texture revealed that the RD-tilted components were a feature of the deformation microstructure. They did not exist in the recrystallization texture that was solely composed of the TD-tilted components, readily after 5 min of annealing (Figure 9a). After completion of recrystallization at $10 \mathrm{~min}$ of annealing, the RD-tilted components were no longer a feature of the overall texture that was only dictated by the TD- recrystallization texture (cf. Figure $9 \mathrm{~b}$ ).

Overall

(a)

(b)

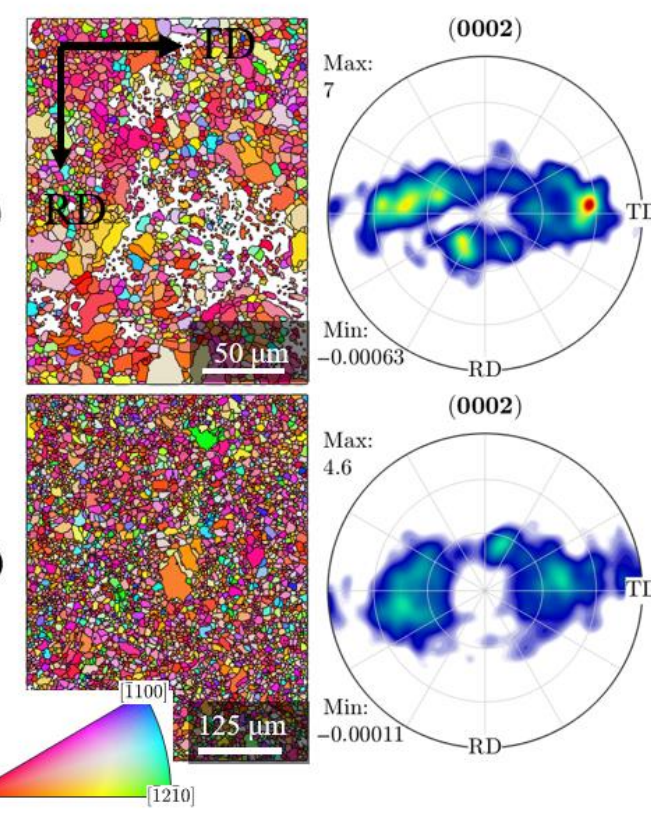

\section{Recrystallized fraction}

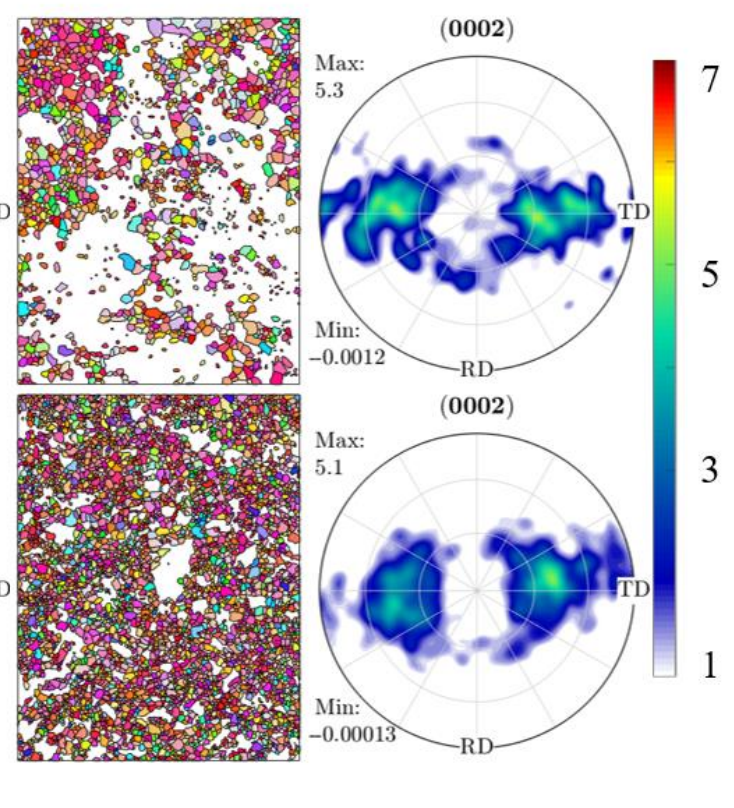

Figure 9. EBSD IPF maps (with respect to ND) and their (0002) pole figures of Mg- $1 \% \mathrm{Er}-1 \% \mathrm{Zn}$ annealed at $350{ }^{\circ} \mathrm{C}$ for $5 \mathrm{~min}$ (a) and $10 \mathrm{~min}(\mathbf{b})$. The left column features the overall map data, and the right column only the recrystallized fraction with GOS $<1^{\circ}$.

Additional grain size vs. texture analysis of the recrystallized structure in Figure $9 \mathrm{~b}$ $\left(400{ }^{\circ} \mathrm{C} / 10 \mathrm{~min}\right.$ ) revealed that the $\pm 40^{\circ} \mathrm{TD}$ texture in the ternary alloy intensifies during recrystallization growth of the nuclei. A similar effect was not observed in the binary system (Figure 10b), as no significant size dependence of texture during recrystallization was found. While there was a progressive texture change in the binary alloy during annealing, which involved both recrystallization and grain growth, the texture change in the counterpart ternary alloy was much more rapid, and in that regard, limited to recrystallization. As the drag force exerted by particles of a given size and volume fraction is too small to match the capillary driving force of grains significantly smaller than the critical grain size $D_{c}$, particle pinning should only play a minor role during recrystallization and early grain growth. Accordingly, selective growth at the recrystallization stage is likely to be governed by solutes. In comparison to the binary alloy, specific boundaries in the ternary alloy seem to break free from their solute atmosphere much sooner enabling texture selection readily during recrystallization. This may be a result of a lower solute content due to the large amount of fine $\mathrm{Er} / \mathrm{Zn}$-rich precipitates, whereas in the binary alloy the $\mathrm{Er}$ content is fully dissolved in the matrix. 

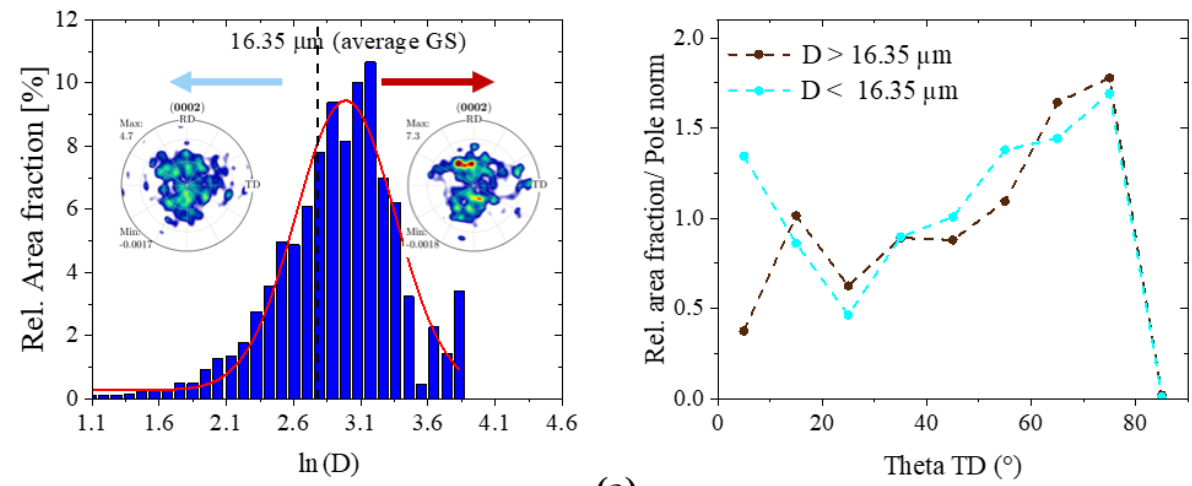

(a)
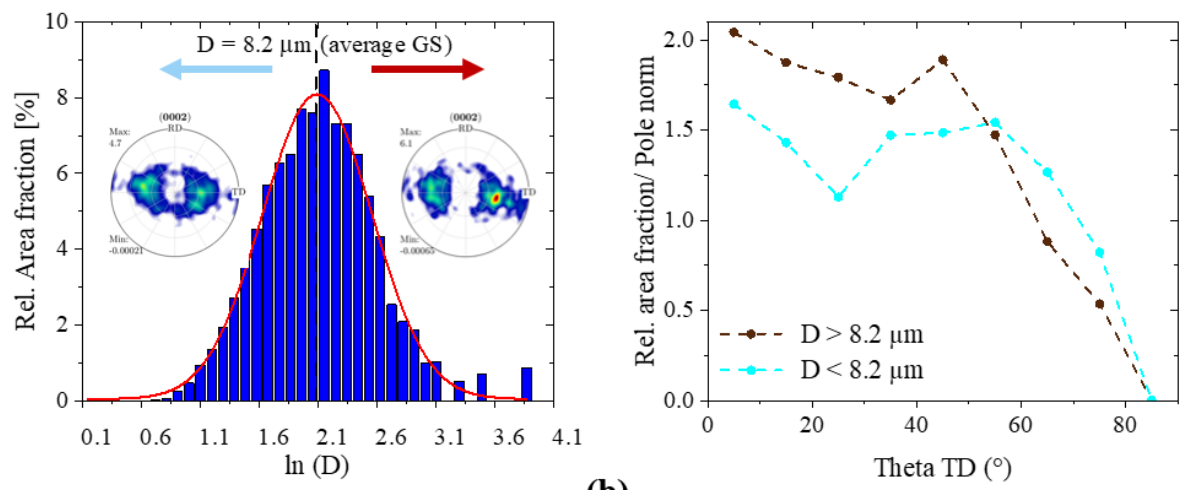

(b)

Figure 10. Grain size distributions from EBSD measurements of $\mathrm{Mg}-1 \% \mathrm{Er}$ annealed at $400{ }^{\circ} \mathrm{C}$ for $4 \mathrm{~min}(\mathbf{a})$ and $\mathrm{Mg}-1 \% \mathrm{Er}-$ $1 \% \mathrm{Zn}$ annealed at $350^{\circ} \mathrm{C}$ for $10 \mathrm{~min}(\mathbf{b})$ along with the orientation distribution of the $\mathrm{c}$-axis with respect to TD for small and large recrystallized grains. The threshold used in each case was the average grain size obtained from EBSD.

The observed recrystallization kinetics of the two alloys further indicates a difference in the drag force during recrystallization. Figure 11 shows the recrystallized volume fraction as a function of annealing time and the corresponding JMAK (Johnson-MehlAvrami-Kolmogorow) fit for both Mg- $1 \%$ Er and Mg- $1 \%$ Er- $1 \% \mathrm{Zn}$ alloys. A Comparison of the recrystallization curves reveals a quicker recrystallization in the ternary alloy $(\sim 210 \mathrm{~s})$ compared to the counterpart binary alloy ( $\sim 50 \mathrm{~s})$. Additionally, the initial stage (linear portion of the curve) until the onset of stable nuclei growth is extended in $\mathrm{Mg}-1 \% \mathrm{Er}$ compared to the other alloy, indicating a longer incubation time in the first. As the incubation time is related to reduced boundary mobility, a stronger solute drag effect in $\mathrm{Mg}-1 \%$ Er may cause a longer incubation period.

Mg- $1 \%$ Er- $1 \%$ Zn exhibited an elevated yield strength, strain hardening capability, and failure ductility. The elevated yield stress is partially caused by precipitation hardening, which contributed by approximately $5 \mathrm{MPa}$ to the $20 \mathrm{MPa}$ offset (approximation by Orowan). Furthermore, the addition of zinc might have magnified the impact of solid solution strengthening by means of synergetic solute effects. To investigate the role of texture and microstructure in the activation of deformation modes during tension, EBSD-assisted slip trace analysis of at least 120 grains per strained sample was employed in the current study. A slip trace appears as a straight line as a result of the intersection of an active slip plane with the free surface. Figure 12 shows the frequency of slip traces corresponding to the active slip systems during $5 \%$ tension in $\mathrm{RD}$, for the binary and ternary alloys. Additionally, the frequency of twinning was evaluated by a visual investigation of each grain. Basal, pyramidal I and $<\mathrm{c}+\mathrm{a}>$ pyramidal II, as well as $\{10 \overline{1} 2\}$ tensile twining were detected with almost equal shares of approximately $22 \%$ in the ternary system. In the binary alloy, basal slip prevailed with about $64 \%$, while all other slip systems accounted for less than $20 \%$ of the overall observed slip traces. A large contribution of basal slip to deformation could justify the lower yield point in the flow curve of the $\mathrm{Mg}-1 \% \mathrm{Er}$ alloy. 
This is because basal slip, even in rare-earth containing $\mathrm{Mg}$ alloys, requires a much lower critical resolved shear stress (CRSS) than non-basal slip [26]. The observed enhanced slip activity on non-basal slip planes in the strained $\mathrm{Mg}-1 \% \mathrm{Er}-1 \% \mathrm{Zn}$ sample can be attributed to both a favorable texture and a change of the CRSS ratio between basal and non-basal slip, evoked by the present $\mathrm{Zn}$ and Er solutes. The relatively low contribution of prismatic slip to deformation might be attributed to the investigated low strain of $5 \%$ being insufficient to activate cross-slip of basal screw dislocations onto the prismatic plane $[27,28]$.

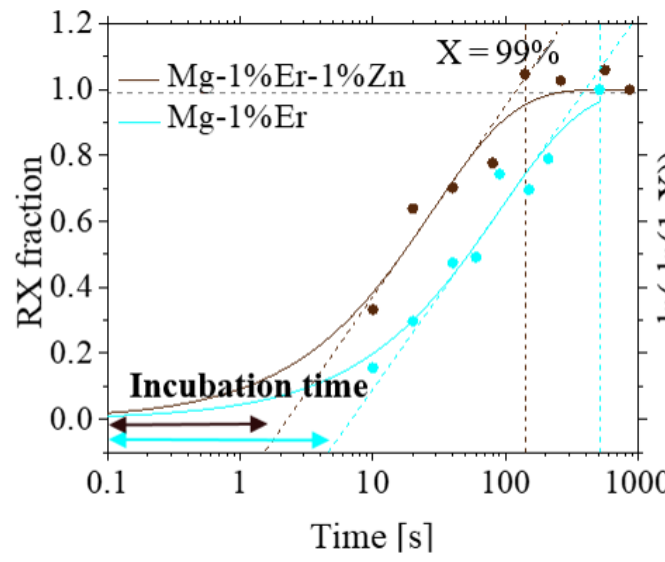

(a)

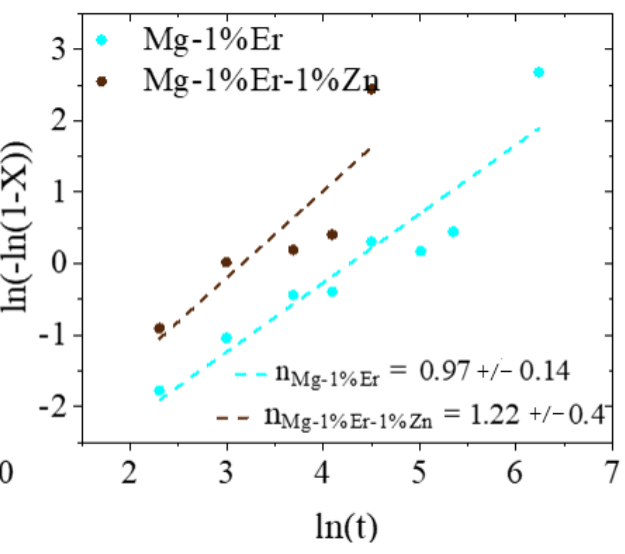

(b)

Figure 11. (a) Recrystallization kinetics of binary and ternary $\mathrm{Mg}-1 \% \mathrm{Er}-(1 \% \mathrm{Zn})$ annealed at $350{ }^{\circ} \mathrm{C}$ and the corresponding Avrami exponents (b).

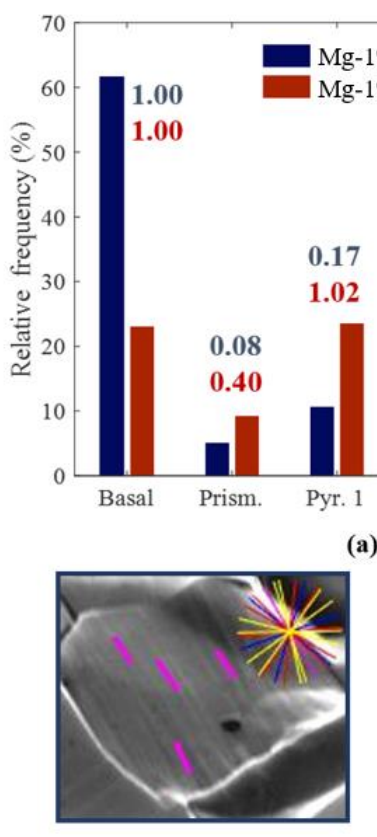

(b)

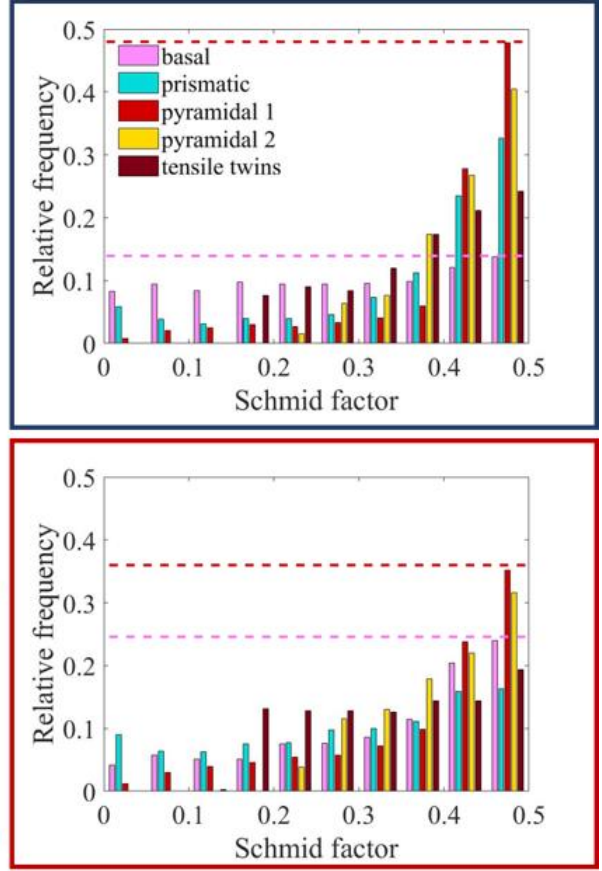

(c)

Figure 12. (a) Distribution of slip traces corresponding to the active slip systems in Mg-1\%Er and Mg-1\%Er- $1 \% \mathrm{Zn}$ during tension to $5 \%$ strain. The initial condition of the sample corresponded to annealing at $400{ }^{\circ} \mathrm{C}$ for $60 \mathrm{~min}$. (b) Exemplary SE images of one grain exhibiting the morphology of slip traces with overlaid possible slip systems obtained from EBSD for the determination of the active slip system. (c) Schmid factor distribution calculated from the initial texture of the grains, in which the slip traces were detected in both alloys. 
Figure 12 also shows the distribution of Schmid factors (SF) of both alloys with respect to the applied external stress corresponding to different slip traces detected. Generally, non-basal slip (particularly pyramidal) seems to be the main plasticity carrier in both alloys. It also seems to comply principally well with the Schmid law, i.e., corresponding slip traces are preferentially detected in grains with the highest $\mathrm{SF}$, and their frequency drops consecutively with decreasing SF. In the binary alloy, it is evident that the activation of basal slip in grains with a very low SF deviates from the Schmid behavior. This is likely due to the naturally low CRSS of basal slip but also to local stress concentrations at grain boundaries that could cause non-Schmid activation of different slip modes. Another important finding from the SF distribution in Figure 12 is the large difference in the contribution of basal vs. non-basal slip to deformation between the two alloys. In the Mg-Er sample at SF $=0.5$, nonbasal slip (including prismatic and both $<a>$ and $<c+a>$ pyramidal slip) was $\sim 2-3$ times more active than basal slip. In contrast, the level of contribution of these slip modes to deformation at $\mathrm{SF}=0.5$ in the $\mathrm{Mg}-1 \% \mathrm{Er}-1 \% \mathrm{Zn}$ sample was more comparable. Both types of pyramidal slip were still preferential with a frequency ratio of $\sim 1.2-1.5$ to basal slip. Prismatic slip was no longer favorable compared to basal slip (frequency ratio of $\sim 0.7$ ).

The present findings certainly highlight the effect of solutes on the deformation behavior, particularly the non-basal slip behavior. There are also indications of solute-induced basal slip strengthening in the current alloys in accordance with previous experimental and computational reports [29-31]. The addition of $\mathrm{Zn}$ that alters the substitutional solute chemistry of the $\mathrm{Mg}-1 \% \mathrm{Er}$ alloy would obviously lead to complex interaction of solute species within the matrix. From energetic perspectives, $\mathrm{Zn}$ and Er can cluster in the lattice to relieve the misfit strains arising from the solute size mismatch. They would also cosegregate to defects in the microstructure, and can be hence expected to have a stronger interaction with grain boundaries and dislocations leading to strikingly different slip system activation during deformation and boundary migration characteristics during annealing. This is indeed demonstrated in the current work by the unique texture development upon rolling and upon annealing of the $\mathrm{Mg}-1 \% \mathrm{Er}-1 \% \mathrm{Zn}$ alloy.

\section{Conclusions}

1. The combination of $\mathrm{Zn}$ and $\mathrm{Er}$ in a dilute substitutional Mg- $1 \% \mathrm{Er}-1 \% \mathrm{Zn}$ alloy (wt \%) led to unique sheet texture development upon rolling and subsequent annealing characterized by pronounced basal pole peaks at $\pm 40^{\circ} \mathrm{TD}$. This type of sheet texture is only common for hcp metals with c/a $<1.633$, such as titanium but was nevertheless observed in the current study.

2. The same texture was not observed in a binary version of the alloy, i.e., $\mathrm{Mg}-1 \% \mathrm{Er}$ subjected to similar processing, which suggests that synergetic effects of multiple solute species, in this case $\mathrm{Zn} / \mathrm{Er}$, are crucial in terms of providing the $\pm 40^{\circ} \mathrm{TD}$ orientations for recrystallization nuclei during deformation and their selective growth during subsequent annealing.

3. Mg- $1 \%$ Er- $1 \%$ Zn alloy obtained a stable final texture $\left( \pm 40^{\circ} \mathrm{TD}\right)$ and grain size $(<20 \mu \mathrm{m})$ upon completion of static recrystallization. By contrast, the binary $\mathrm{Mg}-1 \% \mathrm{Er}$ alloy revealed a continuous modification of its microstructure throughout the annealing process suggesting an important role of grain growth following recrystallization.

4. The microstructural stability of the ternary alloy during longer annealing durations originates from a fine dispersion of dense nanosized particles in the matrix that were found to impede grain growth by Zener drag.

5. Recrystallization nuclei demonstrated selective growth behavior favoring TD-tilted texture components, which was the main mechanism for the $\pm 20^{\circ} \mathrm{RD} \rightarrow \pm 40^{\circ} \mathrm{TD}$ texture transition taking place during recrystallization of the deformed $\mathrm{Mg}-1 \% \mathrm{Er}$ $1 \% \mathrm{Zn}$ alloy. This was likely influenced by solute drag on specific boundaries during early recrystallization. 
6. With respect to the mechanical properties in tension, the addition of zinc, the present precipitates, solute strengthening effects and a favorable soft texture led to a remarkable enhancement in the yield strength, strain hardening capability, and failure ductility as compared with the binary Mg- $1 \%$ Er alloy.

7. EBSD-assisted slip trace analysis at 5\% strain unraveled promoted non-basal slip behavior and obvious basal slip strengthening owing to solute/dislocation interaction that requires extended advanced experimental and computational efforts to better understand the interaction of multiple solute species and solute strengthening.

\begin{abstract}
Author Contributions: Conceptualization, F.-Z.M. and T.A.-S.; Methodology, F.-Z.M. and R.P.; Software, R.P.; Validation, F.-Z.M. and F.S.; Formal analysis, F.-Z.M. and F.S.; Investigation, F.S., R.M., and F.-Z.M.; Resources, S.K.-K. and T.A.-S.; Data curation, F.-Z.M. and T.A.-S.; Writing—original draft preparation, F.-Z.M.; Writing—review and editing, T.A.-S.; Visualization, F.-Z.M.; Supervision, S.K.-K. and T.A.-S.; Project administration, T.A.-S. and S.K.-K.; Funding acquisition, T.A.-S. All authors have read and agreed to the published version of the manuscript.
\end{abstract}

Funding: This research was funded by Deutsche Forschungsgemeinschaft (DFG), grant number grant no. AL 1343/7-1.

Institutional Review Board Statement: Not applicable.

Informed Consent Statement: Not applicable.

Acknowledgments: The financial support of the Deutsche Forschungsgemeinschaft (DFG) under grant no. AL 1343/7-1 is gratefully acknowledged. We also thank Burak Erol for his assistance during the experimental work.

Conflicts of Interest: The authors declare no conflict of interest. The funders had no role in the design of the study; in the collection, analyses, or interpretation of data; in the writing of the manuscript, or in the decision to publish the results.

\title{
References
}

1. Friedrich, H.E.; Mordike, B.L. Technology of Magnesium and Magnesium Alloys. In Magnesium Technology: Metallurgy, Design Data, Applications; Springer: Berlin/Heidelberg, Germany, 2006.

2. Gehrmann, R.; Frommert, M.M.; Gottstein, G. Texture effects on plastic deformation of magnesium. Mater. Sci. Eng. A 2005, 395, 338-349. [CrossRef]

3. Hirsch, J.; Al-Samman, T. Superior light metals by texture engineering: Optimized aluminum and magnesium alloys for automotive applications. Acta Mater. 2013, 61, 818-843. [CrossRef]

4. Imandoust, A.; Barrett, C.D.; Al-Samman, T.; Inal, K.A.; El Kadiri, H. A review on the effect of rare-earth elements on texture evolution during processing of magnesium alloys. J. Mater. Sci. 2016, 52, 1-29. [CrossRef]

5. Hadorn, J.P.; Hantzsche, K.; Yi, S.; Bohlen, J.; Letzig, D.; Wollmershauser, J.A.; Agnew, S.R. Role of Solute in the Texture Modification During Hot Deformation of Mg-Rare Earth Alloys. Metall. Mater. Trans. A 2011, 43, 1347-1362. [CrossRef]

6. Hantzsche, K.; Bohlen, J.; Wendt, J.; Kainer, K.U.; Yi, S.B.; Letzig, D. Effect of rare earth additions on microstructure and texture development of magnesium alloy sheets. Scr. Mater. 2010, 63, 725-730. [CrossRef]

7. Al-Samman, T.; Li, X. Sheet texture modification in magnesium-based alloys by selective rare earth alloying. Mater. Sci. Eng. A 2011, 528, 3809-3822. [CrossRef]

8. Robson, J.D. Effect of Rare-Earth Additions on the Texture of Wrought Magnesium Alloys: The Role of Grain Boundary Segregation. Metall. Mater. Trans. A 2013, 45, 3205-3212. [CrossRef]

9. Barnett, M.R.; Nave, M.D.; Bettles, C.J. Deformation microstructures and textures of some cold rolled Mg alloys. Mater. Sci. Eng. A 2004, 386, 205-211. [CrossRef]

10. Ball, E.A.; Prangnell, P.B. Tensile-compressive yield asymmetries in high strength wrought magnesium alloys. Scr. Metall. Mater. 1994, 31. [CrossRef]

11. Mackenzie, L.; Pekguleryuz, M. The recrystallization and texture of magnesium-zinc-cerium alloys. Scr. Mater. 2008, 59, 665-668. [CrossRef]

12. Basu, I.; Al-Samman, T. Triggering rare earth texture modification in magnesium alloys by addition of zinc and zirconium. Acta Mater. 2014, 67, 116-133. [CrossRef]

13. Jiang, M.G.; Xu, C.; Yan, H.; Lu, S.H.; Nakata, T.; Lao, C.S.; Chen, R.S.; Kamado, S.; Han, E.H. Correlation between dynamic recrystallization and formation of rare earth texture in a Mg-Zn-Gd magnesium alloy during extrusion. Sci. Rep. 2018, 8, 16800. [CrossRef] [PubMed] 
14. Hielscher, R.; Schaeben, H. A novel pole figure inversion method: Specification of theMTEXalgorithm. J. Appl. Crystallogr. 2008, 41, 1024-1037. [CrossRef]

15. Humphreys, F.J.; Hatherly, M. Recrystallization and Related Annealing Phenomena. In Recrystallization and Related Annealing Phenomena; Chapter 9; Elsevier: Amsterdam, The Netherlands, 2004; pp. 285-319. [CrossRef]

16. Lee, H.P.; Esling, C.; Bunge, H.J. Development of the Rolling Texture in Titanium. Textures Microstruct. 1988, 7, 317-337. [CrossRef]

17. Li, M.R.; Deng, D.W.; Kuo, K.H. Crystal structure of the hexagonal (Zn, Mg)4Ho and (Zn, Mg)4Er. J. Alloy. Compd. 2006, 414, 66-72. [CrossRef]

18. Fisher, I.R.; Islam, Z.; Panchula, A.F.; Cheon, K.O.; Kramer, M.J.; Canfield, P.C.; Goldman, A.I. Growth of large-grain R-Mg-Zn quasicrystals from the ternary melt $(\mathrm{R}=\mathrm{Y}, \mathrm{Er}, \mathrm{Ho}$, Dy and Tb). Philos. Mag. B 2009, 77, 1601-1615. [CrossRef]

19. Hadorn, J.P.; Hantzsche, K.; Yi, S.; Bohlen, J.; Letzig, D.; Agnew, S.R. Effects of Solute and Second-Phase Particles on the Texture of Nd-Containing Mg Alloys. Metall. Mater. Trans. A 2012, 43, 1363-1375. [CrossRef]

20. Humphreys, F.J.; Hatherly, M. Grain Growth Following Recrystallization. In Recrystallization and Related Annealing Phenomena; Chapter 11; Elsevier: Amsterdam, The Netherlands, 2004; pp. 333-378. [CrossRef]

21. Lücke, K.; Detert, K. A quantitative theory of grain-boundary motion and recrystallization in metals in the presence of impurities. Acta Metall. 1956, 5, 628-637. [CrossRef]

22. Hillert, M. Solute drag, solute trapping and diffusional dissipation of gibbs energy. Acta Mater. 1999, 47, 4481-4505. [CrossRef]

23. Hutchinson, C.R.; Brechet, Y. Solute Drag: A review of the 'Force' and 'Dissipation' approaches to the efffect of solute on grain and interphase boundary motion. In Termodynamic, Microstructures and Plasticity, Alphonse Finel, Dominique Maziere, Muriel Veron; Springer: Berlin/Heidelberg, Germany, 2003.

24. Kim, S.G.; Park, Y.B. Grain boundary segregation, solute drag and abnormal grain growth. Acta Mater. 2008, 56, 3739-3753. [CrossRef]

25. Barrett, C.D.; Imandoust, A.; El Kadiri, H. The effect of rare earth element segregation on grain boundary energy and mobility in magnesium and ensuing texture weakening. Scr. Mater. 2018, 146, 46-50. [CrossRef]

26. Barnett, M.R. A Taylor Model Based Description of the Proof Stress of Magnesium AZ31 during Hot Working. Metall. Mater. Trans. A 2003, 34, 1799-1806. [CrossRef]

27. Chino, Y.; Kado, M.; Mabuchi, M. Enhancement of tensile ductility and stretch formability of magnesium by addition of 0.2wt\%(0.035at\%)Ce. Mater. Sci. Eng. A 2008, 494, 343-349. [CrossRef]

28. Sandlöbes, S.; Friák, M.; Neugebauer, J.; Raabe, D. Basal and non-basal dislocation slip in Mg-Y. Mater. Sci. Eng. A 2013, 576, 61-68. [CrossRef]

29. Wang, L.; Huang, Z.; Wang, H.; Maldar, A.; Yi, S.; Park, J.-S.; Kenesei, P.; Lilleodden, E.; Zeng, X. Study of slip activity in a Mg-Y alloy by in situ high energy X-ray diffraction microscopy and elastic viscoplastic self-consistent modeling. Acta Mater. 2018, 155, 138-152. [CrossRef]

30. Wu, J.; Si, S.; Takagi, K.; Li, T.; Mine, Y.; Takashima, K.; Chiu, Y.L. Study of basal $<a>$ and pyramidal $<\mathrm{c}+\mathrm{a}>\mathrm{slips}$ in Mg-Y alloys using micro-pillar compression. Philos. Mag. 2020, 100, 1-22. [CrossRef]

31. Tehranchi, A.; Yin, B.; Curtin, W.A. Solute strengthening of basal slip in Mg alloys. Acta Mater. 2018, 151, 56-66. [CrossRef] 